\title{
Education and leadership
}

\section{Engaging patients, users and carers in integrated care}

\author{
Kellie Thomas \\ Business Manager, Inner North West London Integrated Care Pilot, London, UK \\ Benn Keaveney \\ CEO Age Concern Westminster \\ Roz Rosenblatt \\ London Region Manager, Diabetes UK \\ Elisabeth Paice \\ Chair, Inner North West London Integrated Care Pilot and Visiting Professor, Imperial College, London, UK
}

\section{Key messages}

Engaging patients, users and carers takes effort and time, but is a crucial element in implementing integrated care. Third sector involvement is helpful in getting messages across on behalf of their patient groups and in finding representatives for committees. Local patient participation groups are another important source of representatives. It is important to have a diverse group of representatives, to support them with information and to ensure that their voice is heard. Patients, users and carers can bring new insights to health and social care professionals about what matters to themselves and to those they represent.

\section{Why this matters to us}

Benn Keveaney and Roz Rosenblatt co-chair the Patients, Users and Carers Committee of the NWL Integrated Care Pilot, Kellie Thomas leads on patient and user engagement and Elisabeth Paice takes a lead on education within the Pilot. All of us worked from the start of the Pilot to engage patients, carers and users. We share the belief that the need for positive change in practice encompassed both the personal level for the individual and also the improvement of outcomes at population level. We are convinced that engaging patients, carers and users is crucial to the successful implementation of integrated care and in co-designing the education for the staff who will be working in this new way.

\section{ABSTRACT}

Engaging patients, users and carers is an important enabler of integrated care. We describe how the Inner North West London Integrated Care Pilot set up a Patients, Users and Carers Committee, found volunteers to join it, and and helped to prepare them for their role. Representatives from the group were included in the membership of the Pilot's management board and committees and took part in several engagement and educational events. Some obstacles and challenges were encountered, including communicating with a large number of patient participation groups across the area, managing the high expectations of the group about how quickly reforms could be achieved, and ensuring that members of other committees understood the role of the representatives. Benefits included easy access to the perspectives of patients, users and carers when developing the strategy, policies and processes of the Pilot. Representatives proved to be eloquent advocates, and played a part in the success of the Pilot in winning some prestigious awards.

Keywords: patient engagement, integrated care, workforce development, education 


\section{Background}

To support the shift in working practices implied by the introduction of integrated care in North West London and achieve patient empowerment, it is important that those delivering care understand the needs of patients, service users and carers. There is no point in redesigning care delivery around the needs of the patient if healthcare professionals do not understand what the needs are in the first place. ${ }^{1}$ The pilot needed to understand the local networks and how to work 'with' patients, users and carers effectively if positive change was to occur.

\section{Setting}

The Inner North West London Integrated Care Pilot is a local initiative to improve the quality of care for people with diabetes and/or aged 75 and over through better coordination of services and collaboration among providers. This has been more fully described in a recent article in this Journal. ${ }^{2}$

\section{Question}

We were keen to discover whether we could engage patients, users and carers in co-designing aspects of the pilot, and whether their views about what integrated care should offer would be much different from those of the health and social care providers.

\section{Methods}

We contacted Age UK and Diabetes UK, two patient charities relevant to the pilot, and offered them a place on the Integrated Management Board. The establishment agreement that underpinned the Board recognised these charities as partners with 5\% voting rights.

The next step was to establish a Patient, Users and Carers Committee to ensure that the pilot had access to the views of those who were intended to benefit from its activities. Members were sought from across the boroughs through the network of patient participation groups, connections with the third sector and other leads.

To ensure the Committee members were wellinformed, we provided an induction day, including an overview of the pilot and its aims and objectives.
We explained our expectations of the Committee membership, which was to:

- sign up to the principles of integrated care and act as an advocate and champion;

- use their experiences to influence change;

- be a 'critical friend' to the pilot;

- represent the Committee on other committees of the pilot; responding to questions and where necessary escalating views/issues to Board level;

- provide feedback from external patient participation groups and seek views of the wider community.

\section{Results}

Members of the Committee volunteered to act as representatives on other committees of the Integrated Management Board. The pilot was still in the early stages of development and the representatives were able to influence decision-making with regard to an educational strategy, research, pathway design, information technology, financial frameworks and performance review.

A wider group of patients, users and carers contributed to two events where their views were canvassed about the value of a simulated patient pathway as an educational tool for healthcare professionals.

Representatives of the group acted as ambassadors and champions for the pilot by spreading the word within their own networks and by giving interviews, for example, to the $B M J$ and in the NHS Leadership Awards (where the North West London Integrated Care Pilot won the award of NHS Partnership of the Year 2012).

The experience of engaging patients, users and carers was a positive one. A surprising benefit was that their enthusiasm for the vision of better coordinated and more collaborative care kept the team's morale high when the going was difficult. Nonetheless, it required considerable effort. A dedicated member of staff who was able to develop good relationships and communication with a wide network was crucial to success. The obstacles encountered were as follows:

- Sequence of events - it was difficult to engage properly with patients, users and carers before we knew which practices were going to join the partnership, so delays in getting sign-up resulted in delays in engagement. Some keen representatives found that their GPs had not signed up.

- Scale - it was challenging to collaborate effectively with all the local networks for patients, users and carers. 
- Expectations - it was hard to match the high expectations of patients, users and carers about what the pilot could achieve within the available time and resources.

- Communication - we underestimated the effort required to produce information leaflets and other materials about the pilot that would be relevant and readable for patients, users and carers.

- Administrative support - we underestimated the level of administrative support required to run a patients, users and carers group effectively and to keep engagement at a good level.

- Representation - with the support of colleagues from Diabetes UK and Age UK we prepared the Committee representatives well for their role and supported them at their first meetings. However, we failed to appreciate the need to prepare the rest of the Committee membership for including the representatives as full members of the Committee and some early misunderstandings arose.

\section{Discussion/conclusion}

Engaging patients, users and carers is a critical enabler for implementing integrated care. It requires re- sources in terms of administrative infrastructure and expertise. It also requires enthusiasm and commitment so that the involvement is not just for show but genuinely influences the thinking of those leading the changes. Mainly, it requires considerable time and effort from the patients, users and carers themselves, whose input should be recognised, valued and taken into account every step of the way.

\section{REFERENCES}

1 Bate P and Robert G. Experience-based design: from redesigning the system around the patient to co-designing services with the patient. Quality and Safety in Health Care 2006;15:307-10.

2 Steeden A. The Integrated Care Pilot in North West London. London Journal of Primary Care 2013;5:8-11 (online).

\section{ADDRESS FOR CORRESPONDENCE}

Elisabeth Paice.

Email: lispaice@gmail.com

Submitted 11/1/13; revised 15/3/13 